\title{
The IMF's role in structural adjustment
}

\author{
Paul Collier and Jan Willem Gunning
}

\section{WPS/99-18}

June 1999

\begin{abstract}
In the 1980s conditional lending for structural adjustment in developing countries moved the IMF beyond its role of macroeconomic crisis management. Fund-supported adjustment programmes have often been flawed by a lack of distributional analysis and by poor sequencing of reforms, notably premature financial liberalisation. As a result they have caused avoidable hardship. In addition, the attempt to taper out aid as part of the reform programme leads to avoidable reductions in post-stabilisation growth. An important role for the Fund in post-stabilisation environments is to provide credible signals to private investors.
\end{abstract}

World Bank

1818 H Street NW

Washington DC 20433 USA

pcollier@worldbank.org
Centre for the Study of African Economies

St. Cross Building, Manor Road

Oxford OX1 3UL UK

jan.gunning@economics.oxford.ac.uk 


\section{Introduction}

As macroeconomic crises spread across Latin America and Africa during the 1980s, the IMF became much more involved in low-income countries. Whereas following its interventions in developed countries the Fund had rapidly withdrawn post-crisis, in the low income countries its involvement became continuous. This was partly because stabilisation often took longer. However, additionally, by the 1980s it was already evident that whereas those poor countries which had adopted market-based development strategies were developing, those which had adopted inwardoriented, high-regulation strategies were in decline. Unlike the economic crisis of 1998, the crises of the 1980s were concentrated among the inward-orientated. Hence, a reasonable diagnosis was that the crises were not merely manifestations of fiscal imbalance, but that many other policies needed reform. The task thus went beyond the conventional one of rectifying a crisis, to reorienting a development strategy. The Fund joined with the World Bank in an attempt to induce these reforms through sustained conditional lending. Hence, the IMF moved beyond its traditional role of short run, macroeconomic crisis management. Fund and Bank conditions were linked through cross-conditionality, but with the Fund as the lead agency on many areas of policy. This gave the Fund a critical role in structural adjustment.

The Fund's instrument for concessional lending in low-income countries is its Extended Structural Adjustment Facility (ESAF). In 1997 the Board of the Fund commissioned an external review of its ESAF programmes, in which we participated. The Report of the evaluation (Botchwey et al., 1998) suggested three lines of criticism of Fund adjustment programmes and these form the basis of our analysis in this paper. The first is that through flawed design the programmes have sometimes had adverse consequences for the poor, either directly through reducing incomes, or indirectly through reductions in social service provision. Our criticism is of the sequence sometimes adopted by Fund programmes rather than of their content. By the mid-1980s many African economies had accumulated a wide range of dysfunctional policies. Compared with other developing regions, exchange rates were more over-valued, quantitative trade restrictions were more wide ranging, tariffs were higher, agricultural and financial markets were more subject to regulation, and public services were overstaffed relative to expenditures on non-staff inputs. It was thus relatively clear what policies needed to be changed, but since not everything could be reformed at once (whether because of administrative constraints or political will), efficient sequencing raised complex problems in second best theory. Our second criticism is that the extension of the practice of conditionality from the occasional circumstances of crisis management to the continuous process of general economic policy making has implied a transfer of sovereignty which is not only unprecedented but is often dysfunctional. The third criticism is that the programmes have inadvertently resulted in a misallocation of aid resources. The attempt to use aid as an inducement for policy reform has tended to target aid on countries with poor policies where, unless aid happens to induce policy improvement, it is likely to be least effective in reducing poverty. Conversely, the sustained strategy of raising tax revenues while reducing public expenditures has the effect of tapering out the use of aid in precisely those policy environments in which it is most effective.

In section 2 we focus on the first of these critiques. We argue that adjustment programmes have often been flawed by a lack of distributional analysis and by poor sequencing of reforms, notably premature financial liberalisation. As a result the programmes have caused avoidable hardship. In Section 3 we argue that conditionality has generally been ineffective in inducing policy reform, and that the attempt to taper out aid as part of the reform programme leads to avoidable reductions in post-stabilisation growth. However, we suggest that the Fund has an important role to play in poststabilisation environments, through its potential to provide credible signals to private investors. Section 4 concludes. 


\section{The Poverty Impact of Adjustment Programmes}

Since the early 1980s a large number of developing countries have adopted 'structural adjustment programmes', sometimes unilaterally, but more usually at the insistence of donors, under the leadership of the IFIs. Typically these programmes have involved a combination of short-run measures, aimed at stabilisation, and long-run, structural reforms, aimed at transforming heavily controlled economies into market economies. A common criticism is that the policies promoted by the IMF are virtually identical across countries. However, there is considerable heterogeneity. For example, IMF policies aimed to reduce real wages of public sector workers in Cote d'Ivoire, but to raise them in Uganda; to lower tax revenue in Zimbabwe, but to raise it in Ghana; and to introduce ‘stabilising' windfall taxation of coffee exports in Uganda, but to avoid such taxation in Ethiopia. To the extent that the programmes show a marked family resemblance this reflects the prominence of exchange rate adjustment and public expenditure reductions in the stabilisation measures and of trade liberalisation and the abolition of price controls in the set of structural reforms.

From the very start structural adjustment programmes and the Fund's involvement in them have been criticised on the speculation that they would hurt the poor, mainly through reductions in public expenditures on health, education and other social services from which the poor benefited (see, for example, Cornia et al.,1987). This was supported by evidence that social indicators (such as malnutrition and child mortality) worsened in some countries after the adoption of an adjustment programme. Much of this work was quickly recognised as flawed due to both weak data and to the post hoc ergo propter hoc fallacy. Since many of the adjustment programmes arose in circumstances of unsustainable external deficits, and so commenced with a stabilisation phase, the counterfactual was likely to involve declining real expenditure.

Subsequently a more serious literature has developed on the effects of structural adjustment programmes which tends to refute these speculations, although there remain serious methodological problems (see e.g. Corbo and Fischer, 1995, Killick, 1996, Sahn, 1996). Comparisons of adjusting and non-adjusting countries usually fail to control sufficiently for other differences between the two groups. Cross-country regressions can be used to assess the impact of adjustment programmes on macro-economic variables, but they are unsuitable for analysing their distributional impact since there are insufficient data on distributional change: household incomes are measured infrequently. An additional problem in the econometric work is that when a large number of policy changes are adopted simultaneously it becomes difficult to distinguish the effects of policy changes agreed in Fund programmes from other measures.

A rigorous analysis of the distributional impact of adjustment requires good and comparable household survey data. Dercon and Krishnan (1998) analyse poverty changes in Ethiopia, using panel data for six villages. Poverty fell substantially (on various poverty measures) in a period (19891995) of economic reforms. Households with better endowments of physical and human capital saw the largest decline in poverty. However, the Ethiopian data illustrate the problem with comparisons over time: in this same period the households experienced positive weather shocks so that it is unclear how much of the fall in poverty can be attributed to policy changes. At present the best comparable household survey data in Africa are for Uganda, where a series of nationwide surveys of approximately 5,000 households have estimated poverty annually during 1992-97. Since during this period Uganda has implemented far-reaching policy reforms (commonly judged to be the most radical on the continent), this evidence is particularly pertinent. The surveys, analysed by Appleton (1999), show that the incidence of poverty has fallen substantially, regardless of whether it is measured as a simple headcount, by which incidence fell from $56 \%$ to $44 \%$, or more 
sophisticated $\mathrm{P}_{\alpha}$ measures (Foster et al., 1984). The reduction in poverty has been continuous for each year of the surveys. Further, poorer households have gained disproportionately, so that inequality declined, although the major component of poverty reduction came from growth. However, attributing this to the adjustment policies would suffer from the post hoc ergo propter hoc fallacy. In the case of Uganda part of the improvement in the living standards of the poor can however be traced to the liberalisation of agricultural marketing from which poor coffee growers benefited. Appleton shows that while coffee farmers were initially as poor as the average Ugandan the liberalisation enabled them to benefit from the 1994 coffee boom in a way which raised their consumption permanently: consumption did not fall back to pre-boom levels.

In order to avoid false attribution we need a counterfactual. Ideally a general equilibrium model, empirically based on survey data and distinguishing a number of key socio-economic groups is used. This makes it possible to isolate the effects of individual policies and to estimate the resulting income changes for various groups. There has been much work along these lines, including large research programmes at the OECD (e.g. Bourguignon and Morrisson, 1991, Thorbecke, 1991) and at Cornell (e.g. the studies collected in Sahn, 1996) although it has not usually been based upon data as solid as that used by Appleton. The broad conclusion from this literature is that adjustment should benefit the poor in aggregate. This confirms the finding from a large body of microeconomic research that the distortions addressed by adjustment programmes are typically regressive, conferring rents to non-poor groups (Collier and Gunning, 1999). In particular, in many countries the rural poor are net sellers of tradables and therefore they benefit when adjustment programmes rectify exchange rate overvaluation (e.g. Azam, 1992). Also, the poor are typically net buyers of protected importables so that they gain when trade liberalisation reduces the prices of those goods (e.g. Bevan et al., 1990).

General equilibrium analysis of structural adjustment programmes is as yet feasible for only a small number of countries. Also, where general equilibrium models have been used it has typically been expost rather than at the stage of programme design. While a formal analysis based on simulation experiments may not be possible at that stage, it is in many cases possible to identify key distributional effects on the basis of knowledge of the structure of the economy and survey evidence on the distribution of the poor across key socio-economic groups. ${ }^{1}$ The evaluation Report concluded that while this is feasible, it rarely happens in practice. ${ }^{2}$ As a result some subgroups of the poor are avoidably hurt by adjustment programmes.

In analysing the social costs and benefits of adjustment it is useful to distinguish between the two main routes by which living standards are affected by policy: through changes in private incomes and through changes in the provision of social services. Private incomes can change either through quantity effects, such as job loss, or through relative price effects such as a decline in the real wage. A further useful distinction is between adjustment in which policy reform imposes substantial temporary costs in aggregate and those in which losses for some groups arise because of redistributions rather than aggregate changes.

\footnotetext{
${ }^{1}$ In Botchwey et al. (1998) we have shown this on the basis of case studies for a sample of five African ESAF countries: Cote d'Ivoire, Malawi, Uganda, Zambia and Zimbabwe.

${ }^{2}$ One of the exceptions is Malawi where Fund staff carefully considered the implications of the survey evidence that of the rural poor about $40 \%$ were net buyers of maize while the other $60 \%$ were net sellers.
} 
The case of temporary aggregate adjustment costs — where the entire economy initially contracts prior to growth - is typical of the transition economies. The U-shaped response of aggregate income to reform reflects two features of these economies. First, a large sector of the economy, typically industry, produces high-cost inputs, thereby handicapping the expansion of potentially viable sectors and so must contract before such sectors can expand. Secondly, the expansion of the viable sectors is slowed down by a lack of entrepreneurship. In these transitions there are thus temporary aggregate social costs which have the property of an investment since they are necessary to shift the economy onto a higher growth path. If there is a large fall in aggregate income it is likely that most of the initially poor will suffer and that many people not initially poor will join their ranks. Further, most transition economies lack pre-existing safety nets. Typically, there is no public system of welfare payments to the unemployed; there is no easy-entry sector to which workers made redundant in the declining sectors can turn; and the system of support through extended families is relatively weak. The task of protecting the poor from the costs of adjustment may then be closely coincident with the task of helping the poor. On the one hand this simplifies the task of identifying those who need assistance: broad support measures for the poor will be needed. However, it also implies the need for large expenditures upon social protection at a time of declining aggregate resources. Adequate protection of the poor during adjustment may therefore be quite difficult in the transition countries.

Few ESAF countries have the above characteristics. Although part of the economy is not viable at prices which reflect social opportunity costs, notably the import-substitute sector, in ESAF countries this sector is largely making consumer goods rather than inputs for other activities. It is therefore not necessary that it be dismantled prior to the expansion of other activities. There is usually already a large private sector, so that supply response will not in general be held back by an absence of entrepreneurs. An important implication is that adjustment under ESAF programmes rarely involves an unavoidable decline in aggregate income. On the contrary, most of the policy reforms which are necessary for raising growth in the long run can be expected to raise growth in the short run. Indeed, the typical economy should be able to enjoy a phase of unsustainably rapid growth as agents make one-off adjustments to the removal of dysfunctional regulations. In some cases ESAF programmes may nevertheless involve initial reductions in aggregate expenditure because of the need to achieve external viability. Indeed, the macroeconomic crises which have triggered ESAF programmes have more usually taken the form of import compression than of inflation. However, typically import compression has already occurred by the time the Fund is called in, and ESAF programmes increase access to foreign public funding, both directly from the IMF and indirectly from donor and World Bank programmes.

Hence, in most ESAF economies, the intrinsic 'social costs of adjustment' (which may nevertheless be mitigated by offsetting public action) arise through redistributions within society rather than from an unavoidable aggregate contraction in expenditure. However, large redistributions are likely. Partly, these are generated by the relative price changes which are at the core of resource reallocation policies. There are also redistributions generated by changes in public expenditure. Whereas the social costs faced by the transition economies are temporary, the redistributions in the ESAF economies are long-lasting because the relative price changes are permanent. Although some of those adversely affected by adjustment in ESAF economies will be poor, many will not be. If the objective is to compensate those among the poor who lose from adjustment without spending large resources compensating people who do not need it, there is therefore a major task of identification.

In principle all that is needed is information on whether groups are net buyers or sellers of particular commodities and a prediction of the direction in which relative prices will change (cf. Besley and Kanbur, 1991). Analytically each socio-economic group is then treated as a country, so 
that price changes are equivalent to changes in the terms of trade and whether price changes are welfare increasing or reducing depends only on whether the goods concerned are 'imported' or 'exported' by the group. Household surveys often contain this information, indicating, for example, whether a particular group is a net seller of labour or food. The task of efficient public compensation is both reduced and complicated by the presence of well-functioning transfer mechanisms through extended households and kin groups. Many of those among the poor who lose through relative price changes will be cushioned by private transfers. There is thus a case for combining targeting of public compensation programmes with an element of self-selection. Thus, household survey evidence may reveal that a particular area has a high incidence of low-income households which are net sellers of products whose relative price will decline. Public action might be to provide food-for-work schemes in these localities, into which those households which have not been compensated by their families will self-select.

This type of informal analysis is sometimes done prior to the design of an adjustment programme. For example, the first ESAF for Malawi (1988) recognised that a large subset of smallholders, the group which contains the bulk of the country's poor, are net buyers of maize and hence would suffer from the increases in food prices envisaged under the adjustment programme. More commonly, however, such analyses were not performed. For example, again for Malawi, survey data indicated that households which derived most of their income from wage employment on agricultural estates were among the poor. Wages on the estates were set by the government and were not adjusted for a two-year period in which food prices rose sharply. As a result the real incomes of estate workers (many of whom were already poor prior to the reforms) were halved. This income loss was in fact a transfer of income to estate owners and represented an unnecessary cost of adjustment. Had available survey information been used it would have been possible to protect this vulnerable group through nominal wage adjustment, as happened eventually.

Similarly, in Zambia the government for many years operated a system of 'pan-territorial pricing', offering all maize producers the same price, irrespective of their location. Clearly, liberalising maize marketing represented a redistribution of income from farmers in remote areas, most of whom were poor. The terms of trade loss which this group suffered was predictable, but it was not considered in programme design.

There now exists a considerable literature on (and there is substantial practical experience with) instruments to compensate those poor groups which lose under adjustment, e.g. wage adjustments or food-for-work programmes. However, most people, and most of the poor, usually benefit from adjustment programmes, so that badly-targeted safety nets are wasteful. Further, the high-visibility groups which clearly lose from adjustment, such as redundant civil servants and the urban, importconsuming, middle classes, are not poor. This conjunction of diffuse losers among the poor, and compact losers among the non-poor, tends to bias public interventions to mitigate the social costs. Governments have most commonly been pre-occupied by compensating the vocal groups of nonpoor losers. Thus, the most difficult task in protecting the poor from the adverse income effects of programmes is of making them more visible through accurate ex ante identification based on survey evidence.

One reason why this analysis has not usually been included at the design stage is that Fund staff have been recruited for their expertise in macroeconomics. Clearly, Fund staff are not specialised in the analysis of household survey data. They are also less familiar with sectoral analysis. For example, Zimbabwe is one of the few ESAF countries which resembles a transition economy in some respects. At the start of the programme it had a large, diversified industrial sector, much of it producing at high cost inputs which would be needed by potential export activities. Continued 
industrial protection was therefore not feasible in Zimbabwe: protection had to be removed from existing industrial activities before opportunities for manufactured exports could be realised. This feature of the economy was not sufficiently recognised during programme design. Fund projections showed GDP increasing by $18 \%$ over a five-year period (1991-1996). In fact, it increased by only $1 \%$, partly as a result of a $14 \%$ decline in manufacturing GDP. This predictable industrial contraction was thus missed. The estimation of the social impact of this industrial contraction then required some analysis of household survey data.

However, both the sectoral and the household-level analyses needed for a reasonable estimation of the social consequences of adjustments such as the Zimbabwean trade liberalisation are beyond the Fund's traditional expertise. They lie more naturally with the World Bank, which, as a result of its microeconomic focus and heavy involvement in the collection and analysis of household and firm survey data, has a comparative advantage in this area. At present collaboration between the two institutions is somewhat ad hoc. The evaluation Report therefore recommended a more formalised collaboration whereby the Bank would estimate ex ante how various subsets of the poor would be affected by the programme and identify which of them would stand to lose. Safety nets would then be introduced targeted on these groups. Their incomes would then be monitored in the course of the programme so that outcomes could be compared with income paths projected during programme design. If poverty nevertheless severely intensified, then either initial plans were wrong, warranting redesign, or the programme had gone off-track, due to poor implementation or unforeseen events. This approach is now being tested in a pilot phase.

Above we have suggested that outside the context of the transition economies, the policy reforms which constitute structural adjustment should not intrinsically give rise to a phase during which aggregate income declines. Nevertheless, in some ESAF economies such falls have occurred. The case study evidence suggests that sequencing errors in ESAF programmes are an important reason for such anomalous contractions. In Zambia and Zimbabwe a significant part of the decline in income which occurred in both countries in the early years of their adjustment programmes was, in our view, due to premature financial liberalisation. ${ }^{3}$

Zambia and Zimbabwe both adopted adjustment policies at a time when a substantial fiscal stabilisation effort was required. Zimbabwe had (through a system of forced savings involving controlled and negative real interest rates) managed to run huge fiscal deficits (approximately 10\% of GDP) throughout the 1980s. By 1991 the government's domestically held debt had accumulated to $26 \%$ of GDP. Financial liberalisation and fiscal retrenchment were undertaken simultaneously in the case of Zimbabwe. The fiscal projections made in the programme underestimated the huge fiscal burden of financial liberalisation. Interest rate decontrol massively increased government interest payments, adding 5\% of GDP to the deficit. In the event, far from declining as projected, the deficit actually increased. As a result both nominal and real interest rates became very high and volatile, which probably contributed to the sharp fall (9\% in real terms) in total investment in the 1991-96 period. ${ }^{4}$ In effect the early financial liberalisation led to a fiscal crisis. This had serious consequences: the political support for the adjustment programme was undermined as stabilisation became elusive and investment responses to structural reforms failed to materialise.

\footnotetext{
${ }^{3}$ The qualification is that in both countries there was a severe drought which obviously contributed to the contraction.

${ }^{4}$ See Marande and Schmidt-Hebbel (1994) for an analysis of the effect of interest rate increases on private investment.
} 
These outcomes could have been avoided if reforms had been sequenced differently. If financial liberalisation had been postponed, fiscal adjustment would not have had to deal with the additional burden of a sharp increase in interest payments. As fiscal adjustment was achieved, financial liberalisation would have occurred automatically as inflation gradually declined below controlled nominal interest rates.

The Zambia case is quite similar. Here the programme involved a move to capital account convertibility and interest rate liberalisation before stabilisation was achieved. While the inflation rate was still 50\% foreign exchange and domestic financial markets were liberalised, producing a large step increase in the price level. As the country veered towards hyper-inflation the real value of tax receipts was sharply eroded. In response, the government reduced public expenditure by much more than had been envisaged in the programme. The Fund has replied to this critique, arguing that "the urgent need for liberalising the economy, which had been stifled by controls, was so great that the potential short-run costs were probably unavoidable" (Botchwey et al., 1998, p. 139). However, to the extent that the costs were unavoidable, they were presumably reasonably predictable. If there are predictable aggregate costs to a programme it is all the more necessary to analyse them ex ante and to incorporate plans to mitigate their most adverse social consequences.

Both in Zimbabwe and Zambia there was a lack of planning for the consequences of predictable contractions, and the programme sequence probably intensified the temporary declines in both public expenditure and aggregate growth. Through both of these weaknesses the programmes had avoidable adverse effects on poverty.

While financial liberalisation is an example of a structural reform which it might have been better to postpone until stabilisation had been achieved, there are other sequencing issues where there is a case for implementing structural reforms earlier than was envisaged in the programmes. Zambia may again serve as an example. The bulk of the poor in Zambia were in rural areas. Agricultural marketing was under the control of the government and involved, as noted, pan-territorial pricing. Liberalisation would give some rural areas a comparative advantage in export crops. However, the switch from food to cash crops required well-functioning transport, while the rural road network had deteriorated dramatically through lack of maintenance. Hence, in order for the rural poor to realise the gains from trade, it was first necessary to rehabilitate the road network, which would inevitably be a slow process. There was therefore a case for the front-loading of structural reforms (in this case road rehabilitation) but instead such reforms were postponed. By 1996 over 40\% of the rural population was still more than $5 \mathrm{~km}$. away from a bus. The importance of transport is illustrated by the fact that along the line of rail, where the transport network was well developed, a substantial switch to cash crops occurred.

Most seriously, the initial situation was one in which due to the massive subsidy on maize production, few crops other than maize were grown: farmers were in fact producing at a corner solution. This had important implications for the likely response to price liberalisation. New crops might become profitable but there would be few existing growers from whom knowledge about the growing of these crops could be diffused; nor did marketing institutions for these crops exist. In the event there was no emphasis on rural reforms in the early years of the programme while the delay in stabilisation unnecessarily squeezed public expenditures with serious consequences for the road programme. 
Hence the case studies reveal two classes of sequencing errors: those involving premature structural reforms (in particular early financial liberalisation) and, conversely, those involving inappropriately postponed structural reforms. ${ }^{5}$

Table 1: Alternative Measures of Social Expenditures

$\begin{array}{lccc} & & \text { Health } & \text { Education } \\ \text { Zambia } & \text { A } & 91 & 72 \\ 1996(1991=100) & \text { B } & 127 & 124 \\ \text { Zimbabwe } & & & \\ \text { 1995/6 (1990/1=100) } & \text { B } & 81 & 86 \\ \text { Uganda } & & & 69 \\ \text { 1994 (1986=100) } & \text { B } & 209 & 131 \\ & \text { B } & 316 & 208 \\ \text { Malawi } & \text { A } & 113 & 110 \\ 1991(1987=100) & \text { B } & 90 & 88\end{array}$

Note: budget actuals are either deflated by sector-specific GDP deflators (A) or by the aggregate GDP deflator (B). Source: calculated from Botchwey et al. (1998), Table 15 (Zambia), p. 106 (Zimbabwe), Table 14 (Uganda) and Table 11 (Malawi).

Now consider the second channel through which adjustment might affect the poor: public expenditures on social services. The presumption in much of the literature is that the main determinant of changes in service delivery is due to a decline in social expenditures resulting from a decline in public expenditure as a share of GDP. However, this is clearly only one of several determinants of social service provision. First, even if public expenditure is kept stable relative to GDP, total expenditure per capita will decline if per capita GDP falls. Secondly, there may be a reduction in public expenditure relative to GDP. Thirdly, the share of social services in total public expenditure may fall. Fourthly, public services provision may change as a result of changes in the relative price of its inputs. Finally, provision may change because of changes in productivity. The literature has focused on the first three of these channels, and particularly on the third one. Hence time series of expenditure on social services (such as health and education) are commonly presented as percentages of total public expenditure, as a percentage of GDP, or in `real terms' deflated by the GDP deflator. Implicitly it is then assumed that the fourth channel (that of relative price changes) is unimportant and that the GDP deflator is the appropriate deflator for expenditure on social services. This assumption is implausible. Expenditure on education is dominated by wages and salaries and structural adjustment usually involves large real wage changes, in either direction. Expenditure on health care is much more import-intensive because of drugs, and so is sensitive to

\footnotetext{
${ }^{5}$ Mr. Camdessus' summing up of the Fund's Board meeting on the External Evaluation of the ESAF (March 12, 1998) concludes that the "sequencing of fiscal and other structural reforms should be further analysed to minimize any adverse social impact".
} 
the exchange rate. If expenditure on social services appears constant in real terms when using the GDP deflator this may well mask substantial real change.

Table 1 illustrates that relative price changes are in fact large. For example, in Zambia per capita health and education expenditure would appear to have risen sharply in real terms (by about $25 \%$ for both categories) in the period 1991-1996 when the budget actuals are conventionally deflated with the aggregate GDP deflator. However, this conclusion is reversed when sector-specific deflators are used (row A in the Table): expenditure then appears to have fallen in real terms, quite sharply (by $28 \%$ in the case of education). Similarly, for Uganda the conventional presentation exaggerates increases in real expenditure, although here the direction of change is not reversed: social expenditures increase sharply, however they are deflated. For Malawi, however, the Zambia conclusion is reversed: real expenditures fell in terms of the GDP deflator but rose substantially in terms of sector-specific cost indicators.

Fund documents typically report social expenditures either as a share of GDP, or in 'real terms' (deflated by the GDP deflator). The analysis thereby misses large changes in the costs of the provision of social services which come about as a result of programme policies and so are easy to incorporate. In many cases changes in social service provision may be dominated by changes in productivity. These are, however, much harder to predict at the stage of programme design, and a reasonable approach would be to plan only the first four steps in the determination of service delivery. Except in the relatively atypical cases where either a temporary contraction in GDP is unavoidable, or the current account of the balance of payments must be improved, it should not be necessary for planned real per capita public service provision to deteriorate.

\section{Conditionality and Post-Stabilisation Fiscal Tapering}

ESAF programmes have been based upon 'short-leash' conditionality. The Fund and the government negotiate a programme of policy change, to an agreed timetable, and implementation is then monitored. The Fund's internal evaluation of its ESAF programmes recommended that the frequency of monitoring should be increased to quarterly country visits, in effect a shortening of the leash. However, such conditionality inevitably raises questions of government sovereignty.

In economic crises there is a reasonable presumption that the government has committed some serious policy errors. Subject to the need to provide finance rapidly, it is therefore natural that the IFIs should attempt to condition their provision of funds on the agreement by the government to a programme of prospective reform. However, many poor countries now have policy environments which are not characterised by macroeconomic crises. In these post-stabilisation countries there is scope for the role and style of IFI programmes to be somewhat different from the crisis environments.

While a government can legitimately be expected to surrender some of its sovereignty during the short term rectification of a crisis of its own making, it cannot be so expected for the long period during which aid flows can be productively deployed for poverty reduction. Hence, if aid flows in post-stabilisation conditions continue to be conditional upon detailed negotiated promises of policy change they will undermine the government's commitment to the reforms. This is now recognised in the concept of ownership, which was a major theme of the ESAF Report. Detailed promise-based lending outside the context of crisis risks low government commitment to policy change. Also, promise-based aid signals both a divergence of preferences between the recipient and the donor, 
and also a lack of trust. Psychologically, it may induce 'reactance': typically agents who face coercion attempt to re-establish freedom of action by breaching the condition.

These considerations might not matter were it not for the fact that promise-based conditionality faces two major impediments to credible coercion. First, there is a time-consistency problem. Governments have an incentive to agree to, and even to implement, policies which they privately reject. Once the aid has been received they then renege upon the agreement, either by nonimplementation or reversal. Secondly, governments know that aid flows have been heavily influenced by considerations of defensive lending (see Svensson, 1998). Thus, some governments may reasonably believe that a breach of conditions will not be penalised. Burnside and Dollar (1997) test formally whether aid has induced policy change and conclude that there has been no effect. This econometric evidence is supported by actual operational experience. For example, the government of Kenya 'sold' the same agricultural reform to the IFIs five times in fifteen years, while the same commitment to reform was agreed to seven times by governments of Malawi in successive PFPs. Despite the lack of effectiveness of conditionality, policies have generally improved considerably during the past decade. This can more reasonably be attributed to governments learning from the models around them, including from IFI staff, than from the incentive provided by conditional aid programmes.

An important effect of conditional lending has been to distort the allocation of aid. Collier and Dollar (1998) report a regression explaining net aid flows as a function of poverty, population, previous colonial relations, and the policy environment. They measure the policy environment by averaging twenty different aspects of economic policy (including macroeconomic policies, public sector management, corruption and environmental policies) as ordinally rated by World Bank economists. Countries with scores around -2 and below typically have a wide range of policies which would be expected to be economically dysfunctional. Conversely, countries with scores around +2 and above typically have no policies which might be expected to be serious impediments to economic activity. In Figure 1 the "Actual Aid" locus shows the relationship during 1990-96 between the net aid flow as a percentage of the recipient country's GDP $^{6}$ and the policy environment, controlling for the other explanatory variables which are set at their median values. As shown, they find that aid tapers in rapidly in the early stages of policy reform, while tapering out again as policy improves. In effect, donors are targeting their aid flows on poor policy environments in the hope of inducing reform, withdrawing aid once policy reaches a satisfactory level.

To evaluate this relationship of aid to policy we need a benchmark of efficient aid allocation. Collier and Dollar (1999) find that whether aid is effective in raising growth depends upon the policy environment as measured above. The higher is the policy score the larger is the impact of aid upon growth. This corresponds to the results of Burnside and Dollar (1997) in which the policy environment was measured not by the ordinal scoring system of the World Bank, but by a narrower but objectively quantifiable set of macroeconomic policies. Both studies find that aid is subject to diminishing returns, so that policies which are more conducive to growth also increase the absorptive capacity for aid. Collier and Dollar (1999) use the aid-policy-growth relationship to estimate a 'poverty-efficient' allocation of aid. This is an allocation in which the marginal aid cost of a reduction in poverty is the same at each level of policy, controlling for the level of poverty. Because higher policy scores increase absorptive capacity, a poverty-efficient allocation of aid implies that for a given level of poverty, aid should increase as policies become more conducive to

\footnotetext{
${ }^{6} \mathrm{GDP}$ is measured at purchasing power parity exchange rates. Conversion to current exchange rates typically involves multiplying by around three.
} 
growth. Figure 1 depicts the poverty-efficient aid allocation for a country at the median level of poverty but a changing policy score. Note that in this analysis aid should taper in with reform, not as a reward, but simply because with better policies it is more effective in reducing poverty. Aid should only taper out in such environments after prolonged growth has raised incomes sufficiently to reduce the incidence of poverty.

Whereas poverty-efficient aid allocation would taper aid in with policy reform, in fact, aid is provided prematurely, peaking at a level at which it is still ineffective, and then tapers out over precisely the range of policy over which it is highly effective. Evidently, that so much aid is targeted on very poor policy environments is a corollary of promise-based lending: donors attempt to 'buy' policy reform by rewarding promises. However, an even more serious inefficiency is the tapering out of aid in the right-hand half of the figure. Three quarters of the world's poor now live in this range of the policy spectrum.

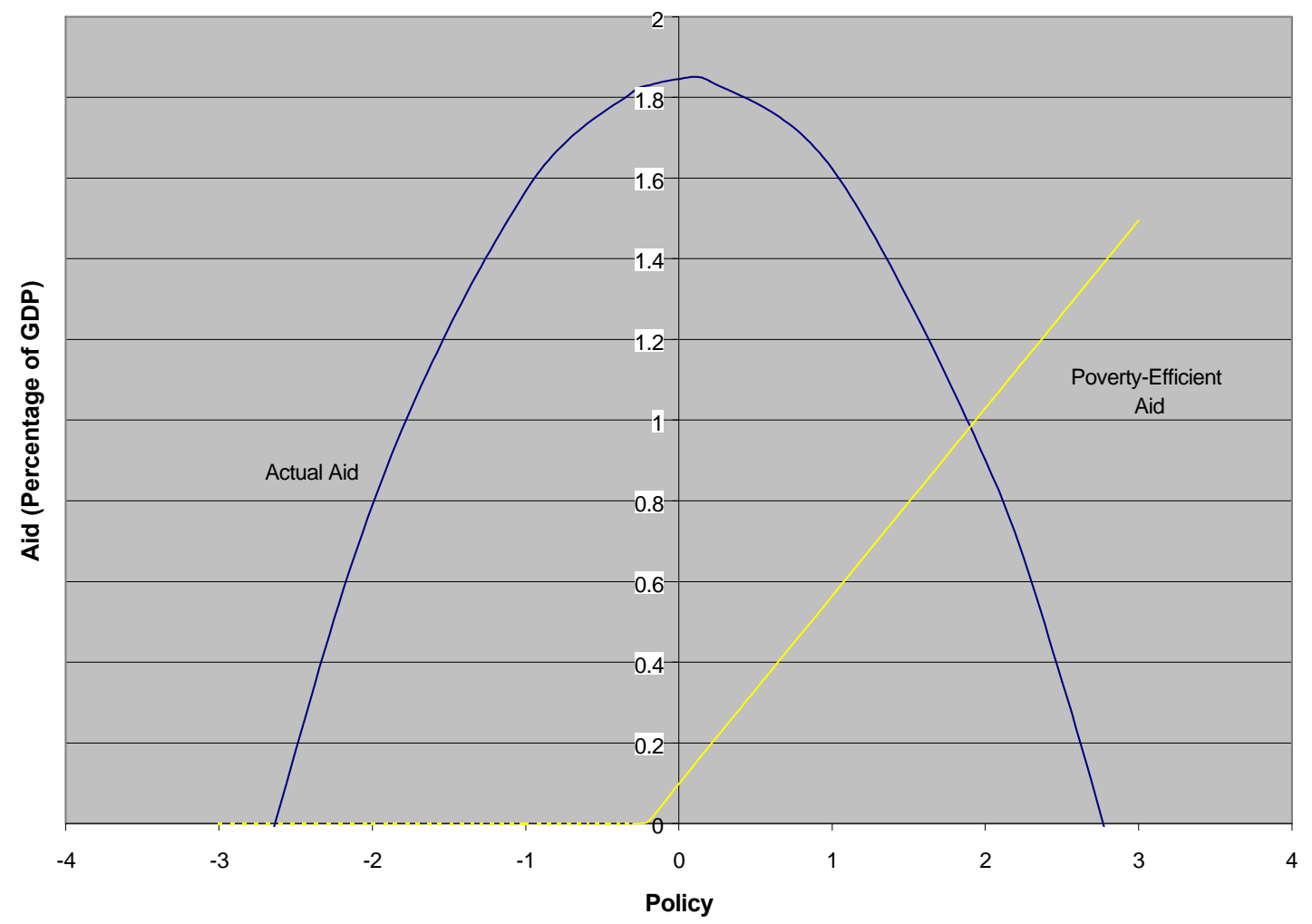

FIGURE 1

We now turn to the phenomenon of premature tapering out. Aid sharply declines in the range of policy improvement which can be thought of as post-stabilisation. This tapering out is not directly related to the attempt to use aid to induce policy reform, but rather is a by-product of a particular definition of what constitutes good policy. A major reason for the premature tapering of aid is that Fund programmes define the fiscal deficit so as to exclude both grants and the grant-equivalent of concessional lending. Large aid flows, even if entirely in the form of grants, are thus reported as 
large fiscal deficits. A major objective of Fund programmes in post-stabilisation environments has been the reduction in the fiscal deficit, so defined.

Clearly, the concept of a fiscal deficit is intended to capture financing behaviour which can rapidly become both costly and unsustainable, notably financing which involves either high inflation or rapid debt accumulation. However, expenditure financed by grants manifestly does not fall into either of these categories. One argument which has been advanced by Fund staff in defence of defining the deficit exclusive of grants is that aid flows are unreliable and so, in the interests of riskreduction, governments must learn to be less aid-dependent. However, many developing countries rely for revenue on trade taxes the receipts from which are highly volatile. Collier (1998) shows that over the past quarter century the average African government has found aid flows to be stabilising, less volatile than revenue and negatively co-variant. A second argument for reducing the fiscal deficit is that this might prevent 'crowding out'. By raising taxes and reducing expenditures governments can run surpluses with the banking system and so 'crowd-in' private investment, a strategy encouraged by the Fund and, for example, pursued in Uganda since the mid-1990s. However, this 'tax and lend' strategy presupposes both a more efficient banking system and a lower marginal cost of taxation than low-income countries usually possess. If the concern is to pass resources to the private sector, a more effective policy may simply be to use some of the aid resources to finance a phase of low taxation. Since low taxation builds the taxable base, it permits a more viable route to fiscal self-reliance than rapid increases in taxation on a weak base.

Given the definition of the fiscal deficit, the objective of tapering it out implies a tapering out of aid. In effect, the Fund has transferred an objective which is entirely reasonable in a context of inflationary financing, to a context in which it is detrimental to growth and poverty reduction. The instrument by which Fund programmes implement the tapering-out of aid is the Policy Framework Paper. Once this is agreed, based on Fund assumptions which project declining aid receipts, any aid receipts beyond this level cannot be spent without breaching the monetary targets. Extra aid can only accumulate as foreign exchange reserves or be used for debt repayment. Naturally, faced with such unappealing uses of their aid, bilateral donors may be unenthusiastic about increasing aid beyond the programme projections. To the extent that 'tapering out' induces a reduction in aid in post-stabilisation environments it constitutes a negative externality of Fund programmes.

So far we have argued that in post-stabilisation environments governments need to be given more freedom to determine economic policy than is appropriate in circumstances of crisis, and that aid should taper in, rather than out, in these environments. A corollary is that the style of IFIgovernment relationship might shift from confrontational negotiation in which promises of policy improvement are extracted, to aid flows conditioned on expost reviews of the level of policy, a role closer to the Fund's other traditional function of surveillance. We now turn to the effect of Fund programmes upon the task of raising private investment.

Typically, the newly reformed low-income countries have been growing quite rapidly. For example in 1995-96 the twelve African countries judged by the World Bank to have the best policies achieved a weighted average growth rate of over $4 \%$ per capita. However, even without the adverse effects of the East Asian crisis, such growth rates were not sustainable given levels of private investment, reflecting the one-off pay-off to the removal of major policy impediments. At normal ICORs investment would need to increase by around 9\% of GDP. Yet here the newly reformed African economies face a problem. Private investors rate such economies very harshly, often based on scanty information. For example, Haque et al. (1998) show that while the three major investor risk ratings are largely explicable in terms of policy fundamentals, they have a high degree of persistence and the dummy for Africa is large and significant. Hence, newly reformed countries in 
Africa find that their ratings are slow to change, and that they are contaminated by a 'bad neighbourhood' effect. Jaspersen et al. (1998) show that the risk ratings are significant in regressions of private investment. Thus, newly reformed governments, the IFIs and donors face a common problem of using the window of opportunity provided by unsustainably easy growth to build up private investment.

One important role for the Fund in encouraging private investment is through facilitating large and increasing aid inflows. Although aid is subject to diminishing returns, in good policy environments aid continues to raise growth rates up to aid/GDP levels of around 12\% (Collier and Dollar, 1998), a much larger net aid inflow than most post-stabilisation low-income economies are currently receiving. Further, in such environments a dollar of aid raises private investment by around $\$ 1.90$ (Burnside and Dollar, 1997). Far from tapering out aid, the Fund should be planning for large aid increases. It should then follow up these plans with the necessary promotion among the donor community, and with reassurance to private investors that the resulting widening of current account payments deficits is not a sign of impending crisis but of sustainable growth.

The second important role for the Fund is to facilitate reputation-building on the part of poststabilisation governments. Obviously, the major players in this task are the governments themselves. However, the Fund has the scope to accredit governments, providing accurate information about the state of the economy. Present practice is detrimental in two respects. First, the reporting of the fiscal deficit so as to exclude grants and the grant-equivalent of concessional lending exaggerates the apparent fiscal deficit. For example, as of 1998 the fiscal deficit for Ethiopia was 8\% of GDP excluding grants and grant-equivalents, but only $0.8 \%$ once these were taken into account, figures which superficially signal very different messages about economic policy management. The international investment community has little time to devote to the circumstances of newly reformed low-income countries and little knowledge of aid accounting. The more transparent are Fund assessments of government performance the greater would be the supply of information to the international investment community. The Report recommended that ESAF programmes should formally distinguish between those which are concerned with crisis management, and those which are post-stabilisation. In this way the Fund would more effectively signal that the post-stabilisation economies should not be confused with the crisis economies.

Secondly, while ever governments are placed in the role of negotiating promises of policy change they face an acute signalling problem. Since Fund negotiators virtually define their role as extracting the maximum possible reform, governments will inevitably be placed in the role of opposing reform at the margin. Further, there is a danger that the credit for those reforms which governments are willing to make will inadvertently accrue to the Fund rather than to the government. Since governments are clearly identified as the owners of policy errors, the past pattern of negotiated policy change may inadvertently have led to government discredit.

\section{Conclusion}

Although it is not a development agency, the Fund has become a key actor in the sphere of development. The Fund gets a natural entry into many low-income economies in times of macroeconomic crises, but, unlike in developed economies, its presence persists long into the poststabilisation phase. In the process the Fund has expanded its remit from macroeconomics to a wide range of microeconomic policies. We have suggested that this raises three core questions. 
First, it should not be in dispute that many countries needed to implement the reforms which the Fund and the Bank have attempted to negotiate. However, the ideal sequence of implementation and its distributional impact are both complex issues on which judgements can reasonably be questioned. Sequencing raises second best considerations, and the distributional impact of reform requires general equilibrium analysis combined with household survey data, areas of analysis which range beyond the traditional competence of most Fund staff.

Secondly, the extension of the style of negotiated policy reform in exchange for financing from the temporary and narrowly focussed context of macroeconomic crisis to the semi-permanent and allembracing context of long term development in already stabilised economies, constitutes a major encroachment on government sovereignty. There is evidence that this relationship between governments and the International Financial Institutions (IFIs) is rather ineffective in achieving sustained policy reform, while it tends to remove from reforming governments the capacity to signal their true type to potential investors. We have suggested that a move by the Fund to an $e x$ post assessment of post-stabilisation environments, more akin to its traditional role in surveillance, is better suited to reputation-building.

Thirdly, the carry-over of the objective of fiscal deficit reduction from crisis environments where it is often necessary to the context of post-stabilisation is inappropriate. The Fund currently defines the fiscal deficit as exclusive of aid, so that its attempts to reduce fiscal deficits are equivalent to a tapering out of aid. Yet it is precisely in the post-stabilisation, reasonable policy environments where aid can be shown to be most effective in growth, the recovery of private investment, and in poverty reduction. The tapering out of aid over precisely the policy range in which it should taper in, is a major resource misallocation for which the IFIs and the donor community must collectively take responsibility, since it is obviously not determined by recipient governments. To the extent that this donor behaviour is induced by Fund programmes it may constitute a negative externality.

World Bank and University of Oxford

University of Oxford and Free University, Amsterdam 


\section{References}

Appleton, S. (1999). 'Changes in Poverty in Uganda, 1992-1997.' Mimeo, Centre for the Study of African Economies, University of Oxford.

Azam, J.-P. (1992). 'The Uncertain Distributional Impact of Structural Adjustment in Sub-Saharan Africa.' In Structural Adjustment and Beyond in Sub-Sabaran Africa (eds. R. van der Hoeven and F. van der Kraaij). London: Currey.

Besley, T. and R. Kanbur (1991). 'The Principles of Targeting'. In Current Issues in Development Economics (eds. V.N. Balasubramanyam and S. Lall). London: Macmillan, pp. 69-90.

Bevan, D, P. Collier and J.W. Gunning (1990). Controlled Open Economies: a Neoclassical Approach to Structuralism. Oxford: Oxford University Press (Clarendon).

Botchwey, K., P. Collier, J.W. Gunning and K. Hamada (1998). Report by a Group of Independent Experts: External Evaluation of the ESAF. Washington, DC: IMF.

Bourguignon, F. and C. Morrisson (1991). Adjustment and Equity in Developing Countries: a New Approach. Paris: OECD.

Burnside, C. and D. Dollar (1997). `Aid, Policies and Growth.’ Policy Research Working Paper No. 1777, World Bank.

Collier, P. (1998). 'Aid Dependency: a Critique'. Forthcoming in the Journal of African Economies.

Collier, P. and D. Dollar (1998). 'Aid Allocation and Poverty Reduction.' Mimeo, DRG, World Bank.

Collier, P. and J.W. Gunning (1999). 'Explaining African Economic Performance.' Journal.of Economic Literature, vol. 37, pp. 64-111.

Corbo, V. and S. Fischer (1995). 'Structural Adjustment, Stabilization and Policy Reform: Domestic and International Finance.' In Handbook of Development Economics, vol. 3B, (eds. J.R. Behrman and T.N. Srinivasan). Amsterdam: North-Holland.

Cornia, A., R. Jolly and F. Stewart (1987). Adjustment with a Human Face. Protecting the Vulnerable and Promoting Growth. Oxford: Oxford University Press (Clarendon).

Dercon, S. and P. Krishnan (1998). 'Changes in Poverty in Rural Ethiopia 1989-1995: Measurement, Robustness Tests and Decomposition.' Working Paper 98-7, Centre for the Study of African Economies, University of Oxford.

Foster, J., J. Greer and E. Thorbecke (1984), 'A Class of Decomposable Poverty Measures.' Econometrica, vol. 52, pp. 761-766.

Haque, N.U., M. Nelson and D.T. Mathieson (1998). 'Creditworthiness Ratings: Their Political and Economic Content.' Forthcoming in Investment and Risk in Africa (eds. P. Collier and C. Pattillo). London: Macmillan.

Jaspersen, F.Z., A.H. Aylward and A.D. Kox (1998). 'The Effects of Risk on Private Investment: Africa Compared with other Developing Areas.' Forthcoming in Investment and Risk in Africa (eds. P. Collier and C. Pattillo). London: Macmillan.

Killick, T. (1996). 'Principals, Agents and the Limitations of BWI Conditionality.' The World Economy, vol. 16, pp. 211-229.

Marande, F. and K. Schmidt-Hebbel (1994). 'Zimbabwe: Fiscal Disequilibria and Growth.' In Public Sector Deficits and Macroeconomic Performance (eds. W. Easterly et al.). New York: Oxford University Press.

Sahn, D. (ed.) (1996). Economic Reform and the Poor in Africa. Oxford: Oxford University Press (Clarendon).

Svensson, J. (1998). 'Aid Tournaments.' Mimeo, DRG, World Bank.

Thorbecke, E. (1991). 'Adjustment, Poverty and Income Distribution in Indonesia.' World Development, vol. 19, pp. 1595-1614. 